\title{
Maximum potential benefit of implantable defibrillators in preventing sudden death after hospital admission because of heart failure
}

\author{
Soko Setoguchi MD DrPH, Anju Nohria MD, Jeremy A. Rassen ScD, Lynne Warner Stevenson MD, \\ Sebastian Schneeweiss MD ScD
}

$\infty \quad$ See related commentary by Dorian, page 599

\section{ABSTRACT}

Background: Implantable defibrillators are recommended for the prevention of sudden cardiac death in patients with heart failure. However, criteria to identify those who would benefit most from this therapy are lacking. We assessed the maximum potential benefit of preventing sudden death in patients with repeated hospital admissions because of heart failure.

Methods: Using a cohort assembled from an administrative database, we identified 14374 patients admitted to hospital for the first time because of heart failure between Jan. 1, 2000, and Dec. 31, 2004. We followed subsequent admissions related to heart failure as well as mortality and causes of death to Mar. 31, 2006. We regarded all out-of-hospital cardiac deaths as sudden deaths. We calculated the maximum potential benefit of preventing sudden death by subtracting the observed survival after each hospital admission from the hypothetical survival whereby all out-of-hospital cardiac deaths were assumed to be preventable.

Results: The mean age of the cohort was 77 years, $45 \%$ were women, $11 \%$ had cerebrovascular disease, and $21 \%$ had chronic kidney disease. Out-of-hospital cardiac deaths constituted 13.7\% (1226/8967) of all deaths during 32055 person-years of follow-up. The median survival declined with each subsequent hospital admission related to heart failure. The hypothetical prevention of all out-of-hospital deaths prolonged life by 0.63 (95\% confidence interval $[\mathrm{Cl}]$ 0.49 to 0.77 ) years after the first hospital admission. This potential benefit dropped to $0.28(95 \% \mathrm{Cl} 0.10$ to 0.46$)$ years after 3 hospital admissions related to heart failure. Among patients less than 65 years old, and older patients without kidney disease, dementia or cancer, more than $50 \%$ survived longer than 2 years until they had 2 or 3 hospital admissions related to heart failure.

Interpretation: The use of implantable defibrillators to prevent sudden death would provide limited benefit among older patients with comorbidities and among patients with multiple hospital admissions related to heart failure.

Une version française de ce résumé est disponible à l'adresse www.cmaj.ca/cgi/content/full/180/6/611/DC1

CMAJ 2009;180(6):611-6
$\mathrm{T}$ he burden of heart failure is substantial, accounting for 106130 related hospital admissions and 1.38 million days in hospital in 2001 in Canada. ${ }^{1}$ In the United States it accounted for 1.09 million related hospital admissions in $2003 .{ }^{2}$ One of the new management options, implantable cardioverter defibrillators have been shown to be beneficial in study populations of patients with heart failure and a low ejection fraction. However, trials often exclude older patients and patients with clinically significant comorbidities. It is unclear how the benefit of preventing sudden cardiac death would translate to the community setting, where patients with heart failure are typically older and have more comorbidities than patients in clinical trials.

Having repeated admissions to hospital because of heart failure has been shown to be a predictor of death. ${ }^{3}$ However, death in patients with heart failure can be due to sudden cardiac arrest, terminal pump failure or a comorbid condition. The potential contribution of preventing sudden death to the survival of patients in the community with repeated hospital admissions because of heart failure has not previously been studied.

We conducted a study in a large regional population to assess the maximum potential benefit of preventing sudden death with implantable defibrillators in terms of overall survival in relation to the number of hospital admissions because of heart failure. We also examined the causes of death and identified subgroups of patients who might benefit the most from implantable defibrillators.

\section{Methods}

\section{Data sources and study population}

We used data for the period 1996-2006 obtained from health care utilization databases that contain basic demographic information as well as discharge abstracts, outpatient diagnoses, procedure codes and drug-dispensing data for residents in the province of British Columbia, Canada. These data sources have been shown to have high levels of coding accuracy. ${ }^{4}$ The discharge abstract provided up to 25 fields for diagnoses and 10 fields for procedures that were relevant during hospital stays.

From the Division of Pharmacoepidemiology and Pharmacoeconomics (Setoguchi, Rassen, Schneeweiss) and the Advanced Heart Disease Section, Division of Cardiovascular Medicine (Nohria, Stevenson), Department of Medicine, Brigham and Women's Hospital and Harvard Medical School, Boston, USA 
We assembled a cohort of all patients who were admitted to hospital for the first time because of heart failure between Jan. 1, 2000, and Dec. 31, 2004. We included admissions that had heart failure as the primary discharge diagnosis (International Classification of Diseases, ninth revision, clinical modification [ICD-9-CM] code 428). This diagnostic code or the corresponding ICD-10 code has previously been shown to have a positive predictive value of $94 \%$ for heart failure using the Framingham criteria. ${ }^{5}$ Patients who had been admitted to hospital with heart failure within the 4 years before the index admission were excluded.

For patients included in the study, we assessed their char-

Table 1: Characteristics of patients at their first hospital admission because of heart failure

\begin{tabular}{|c|c|}
\hline Characteristic & $\begin{array}{c}\text { No. (\%) of patients* } \\
\quad n=14374\end{array}$ \\
\hline \multicolumn{2}{|l|}{ Age, yr } \\
\hline Mean (SD) & $77.1(12.0)$ \\
\hline$<55$ & $712 \quad(5.0)$ \\
\hline $55-64$ & 1212 \\
\hline $65-74$ & $2880(20.0)$ \\
\hline $75-84$ & $5472(38.1)$ \\
\hline$\geq 85$ & $4098(28.5)$ \\
\hline \multicolumn{2}{|l|}{ Sex } \\
\hline Male & $7833(54.5)$ \\
\hline Female & $6541(45.5)$ \\
\hline \multicolumn{2}{|l|}{ Prior hospital admission } \\
\hline For any reason & $11482(79.9)$ \\
\hline $\begin{array}{l}\text { Because of cardiovascular event other } \\
\text { than heart failure }\end{array}$ & $7211(50.2)$ \\
\hline \multicolumn{2}{|l|}{ Comorbidity } \\
\hline Myocardial infarction & $2550(17.7)$ \\
\hline Ischemic heart disease & $6773(47.1)$ \\
\hline Cerebrovascular disease & $1644(11.4)$ \\
\hline Atrial fibrillation or flutter & $5232(36.4)$ \\
\hline $\begin{array}{l}\text { Ventricular tachycardia, ventricular } \\
\text { fibrillation or cardiac arrest }\end{array}$ & $328 \quad(2.3)$ \\
\hline Hypertension & $10183(70.8)$ \\
\hline Diabetes mellitus & $5150(35.8)$ \\
\hline Cancer & 1273 (8.9) \\
\hline \multicolumn{2}{|l|}{ Chronic kidney disease } \\
\hline No dialysis & $2975(20.7)$ \\
\hline Dialysis & $289 \quad(2.0)$ \\
\hline Chronic pulmonary disease & $3421(23.8)$ \\
\hline Rheumatoid arthritis & $215 \quad(1.5)$ \\
\hline Dementia & $886 \quad(6.2)$ \\
\hline \multicolumn{2}{|l|}{ Treatment } \\
\hline Defibrillator implantation & $65 \quad(0.5)$ \\
\hline Any pacemaker implantation & 1061 (7.4) \\
\hline
\end{tabular}

Note: SD = standard deviation.

*Unless stated otherwise. acteristics and comorbidities during the 4 years before the index admission. The comorbid conditions included a history of myocardial infarction, other ischemic heart disease, cerebrovascular disease, atrial fibrillation, cardiac arrest or ventricular arrhythmia, hypertension, diabetes mellitus, chronic kidney disease, chronic pulmonary disease, cancer, rheumatoid arthritis and dementia. These conditions were defined by the presence of corresponding ICD-9-CM or ICD-10 diagnostic codes in hospital discharge abstracts or outpatient files, or both. Many of the definitions used have been previously validated. ${ }^{6-10}$ The definition of myocardial infarction has been validated by means of medical chart review to have a positive predictive value of $94 \% .{ }^{8}$ We used a definition of chronic kidney disease previously shown to have a positive predictive value of $94 \%$ compared with an estimated glomerular filtration rate of less than $60 \mathrm{~mL} / \mathrm{min}$ per $1.73 \mathrm{~m}^{2}{ }^{9}$ Cardiac arrest or ventricular arrhythmia was defined by ICD-9-CM or ICD-10 codes in hospital discharge abstracts previously shown to have a positive predictive value of $82 \% .^{10}$

The institutional review boards of the Brigham and Women's Hospital and the University of Victoria approved the study design; data-use agreements were established. All potentially traceable personal identifiers were removed from the data before analyses to protect patients' privacy.

\section{Causes and sites of death}

All patients were followed until they died or until the end of the study period (Mar. 31, 2006). To characterize survival after each hospital admission related to heart failure, we estimated mortality after the first admission by using the survival time from the index admission until death or the end of follow-up. For subsequent hospital admissions related to heart failure, we estimated the mortality after each admission by using the survival time from that admission until death or the end of follow-up.

We obtained information on causes of death from death certificates. We categorized the causes into 4 main groups: inhospital cardiac death, in-hospital noncardiac death, out-ofhospital cardiac death and out-of-hospital noncardiac death. We defined all out-of-hospital cardiac deaths as sudden deaths outside of acute care hospitals that had cardiac disease recorded as the underlying cause of death. ${ }^{11}$

We assessed the site of residence of patients at the time of out-of-hospital cardiac death by identifying any use of long-term care benefits. We categorized the site of residence as home, independent living; home, with home or daycare support; residential nursing home; or hospice. We used the claims information on admissions to acute care hospitals and uses of long-term care services to determine the place of death and site of residence. The information is used for payment and has been shown to be highly accurate. ${ }^{12}$

\section{Benefit of preventing sudden death}

We calculated the maximum potential benefit of preventing sudden death as the difference between the hypothetical survival if there were no out-of-hospital cardiac deaths and the observed median survival. We did the same calculation after 
each hospital admission related to heart failure. We assumed that all out-of-hospital cardiac deaths were sudden arrhythmic events that are potentially preventable. Although many causes of out-of-hospital cardiac death are not preventable, we used this definition to provide the outside boundary for the potential impact of preventing sudden death.

\section{Statistical analysis}

For the observed survival, we conducted Kaplan-Meier survival analyses and plotted mortality curves after each hospital admission. For the hypothetical survival, under the assumption of complete prevention of sudden death with the use of implantable defibrillators, we censored all out-of-hospital cardiac deaths and plotted Kaplan-Meier curves after each hospital admission related to heart failure. We assessed the potential maximum benefit by calculating the difference between the hypothetical survival and the observed median survivals. We used a bootstrap method to estimate the variance and $95 \%$ confidence limit (CI) of the difference in median survival between the hypothetical and observed rates. Consistent with the bootstrap principle, we replicated the data-generation process by randomly sampling patients with replacement from the original cohort. In each bootstrap sample, we estimated the observed and hypothetical median survival rates using Kaplan-Meier analysis and calculated the difference between the rates after each hospital admission. We repeated the process 1000 times to estimate the variance and 95\% CIs of the estimated survival difference.

We identified subgroups of patients who would likely benefit the most from the prevention of sudden death. We did this by estimating a hypothetical 2-year survival rate in each sub- group characterized by age and presence of comorbidities that are strong predictors of sudden death or overall mortality, such as advanced age, kidney disease, cancer and dementia. ${ }^{3}$ We chose a 2-year timeframe because randomized trials have shown that the survival benefit of implantable defibrillators became apparent only about $1-1.5$ years after implantation. ${ }^{13,14}$ We used a bootstrap method to estimate the $95 \%$ CI of the 2year survival rates.

\section{Results}

\section{Study population}

We identified a cohort of 14374 patients who were admitted to hospital for the first time because of heart failure between Jan. 1, 2000, and Dec. 31, 2004. Characteristics of the study population are summarized in Table 1. The mean age of the cohort was 77 years. Patients had a high prevalence of comorbid conditions, including other cardiovascular diseases, diabetes, chronic pulmonary disease and chronic kidney disease. The mean length of follow-up was 2.2 (standard deviation 1.8) years.

Of the 14374 patients, 4303 had two, 1681 had three, and 713 had four hospital admissions because of heart failure during the study period. The median number of days between admissions was 160 (interquartile range 39-516) between the first and second, 96 (interquartile range 29-291) between the second and third, and 62 (interquartile range 23-230) between the third and fourth admissions. The prevalence of major comorbidities increased with the increasing number of admissions because of heart failure (Table 2).

Table 2: Change in selected characteristics of the study population after each hospital admission because of heart failure

\begin{tabular}{|c|c|c|c|c|}
\hline \multirow[b]{2}{*}{ Characteristic } & \multicolumn{4}{|c|}{ Hospital admission; no. (\%) of patients* } \\
\hline & $\begin{array}{c}\text { First } \\
n=14374\end{array}$ & $\begin{array}{l}\text { Second } \\
n=4303\end{array}$ & $\begin{array}{l}\text { Third } \\
n=1681\end{array}$ & $\begin{array}{l}\text { Fourth } \\
n=713\end{array}$ \\
\hline Age, yr, mean (SD) & $77.1(12.0)$ & $78.9(11.2)$ & $79.4(11.1)$ & $79.8(10.6)$ \\
\hline Sex, male & $7833(54.5)$ & $2320(53.9)$ & $877(52.2)$ & $352(49.4)$ \\
\hline Myocardial infarction & $2550(17.7)$ & $984(22.9)$ & $478(28.4)$ & $215(30.2)$ \\
\hline Cerebrovascular disease & $1644(11.4)$ & $544(12.6)$ & $240(14.3)$ & $110(15.4)$ \\
\hline Atrial fibrillation or flutter & $5232(36.4)$ & $1792(41.6)$ & $801(47.7)$ & $388(54.4)$ \\
\hline $\begin{array}{l}\text { Ventricular tachycardia, ventricular } \\
\text { fibrillation or cardiac arrest }\end{array}$ & $328 \quad(2.3)$ & $130(3.0)$ & $67(4.0)$ & $38 \quad(5.3)$ \\
\hline \multicolumn{5}{|l|}{ Chronic kidney disease } \\
\hline Dementia & $886 \quad(6.2)$ & $208(4.8)$ & $107 \quad(6.4)$ & $50 \quad(7.0)$ \\
\hline Defibrillator implantation & $65 \quad(0.5)$ & $30(0.7)$ & $19(1.1)$ & 11 (1.5) \\
\hline Any pacemaker implantation & $1061 \quad(7.4)$ & $472(11.0)$ & $247(14.7)$ & $117(16.4)$ \\
\hline
\end{tabular}

Note: SD = standard deviation.

*Unless stated otherwise. 
Table 3: Causes and sites of death among patients admitted to hospital with heart failure

\begin{tabular}{lr}
\hline Site; cause of death & $\begin{array}{c}\text { No. (\%) of deaths } \\
n=8967\end{array}$ \\
\hline $\begin{array}{l}\text { In hospital } \\
\text { Noncardiac death }\end{array}$ & $3400(37.9)$ \\
\hline $\begin{array}{l}\text { Cardiac death } \\
\text { Out of hospital }\end{array}$ & $1955(26.3)$ \\
$\begin{array}{l}\text { Noncardiac death } \\
\text { Cardiac death* }\end{array}$ & $1226(13.7)$ \\
\hline $\begin{array}{l}\text { Residential nursing home } \\
\text { Home, independent living }\end{array}$ & $525 \quad(6.1)$ \\
\hline $\begin{array}{l}\text { Home, with home or daycare } \\
\text { support }\end{array}$ & $148 \quad(1.7)$ \\
\hline Hospice & $10 \quad(0.1)$ \\
\hline
\end{tabular}

*Defined as death occurring out of acute care hospital with the underlying cause of death reported as cardiac disease.

\section{Causes and sites of death}

A total of 8967 patients died during a mean follow-up of 2.2 years. The distribution of the causes is shown in Table 3 . There were 1226 (13.7\%) out-of-hospital cardiac deaths. Of these deaths, most involved patients in residential nursing homes $(44.3 \%)$ and those living independently at home $(42.8 \%)$; a small proportion $(12.1 \%)$ were receiving some kind of home or daycare support at home.

\section{Effect of preventing sudden death on survival}

The median survival declined sharply after repeated hospital admissions, even when we assumed that all out-of-hospital cardiac deaths were preventable (see Appendix 1, available at www.cmaj.ca/cgi/content/full/180/6/611/DC2). The maximum potential benefit from the prevention of sudden death was about 0.63 (95\% CI 0.49 to 0.77 ) years after the first hospital admission (Figure 1). The difference between observed survival and hypothetical survival diminished progressively after each subsequent admission, from 0.37 (95\% CI 0.20 to
$0.55)$ years after 2 hospital admissions, to 0.28 (95\% CI 0.10 to 0.46 ) years after 3 admissions, to 0.20 (95\% CI -0.04 to 0.45 ) years after 4 admissions. When we conducted a sensitivity analysis in which we excluded 65 patients who had implantable defibrillators at baseline and censored upon implantation 119 patients who subsequently received implantable defibrillators during follow-up, we found similar results to those of the main analysis: 0.63 after the first admission, 0.37 after the second, 0.27 after the third and 0.22 after the fourth.

Table 4 shows the observed and hypothetical 2-year survival rates after each subsequent hospital admission in each subgroup of patients defined by age and the presence of kidney disease, dementia or cancer. We found that, among patients less than 65 years of age, more than $50 \%$ survived more than 2 years regardless of kidney function until they had 2 or 3 hospital admissions related to heart failure. Patients aged 65-80 years who were free of kidney disease or dementia also had a good prognosis, even after repeated hospital admissions, compared with those who had these comorbidities. Patients aged 80-90 who did not have kidney disease, dementia or cancer had a good prognosis at the time of their first hospital admission but not after subsequent admissions. Patients over 90 years old had a poor prognosis regardless of the presence of other comorbidities.

\section{Interpretation}

In this study, we noted that the contribution of out-of-hospital cardiac deaths to the overall survival was small, especially among patients living independently. The overall mortality among patients with repeated hospital admissions related to heart failure would have remained high even if all out-ofhospital cardiac deaths were prevented with the use of implantable defibrillators. This lack of benefit would be more pronounced among patients of advanced age who have comorbid illnesses that decrease overall survival and who have had multiple hospital admissions because of heart failure. As a corollary, patients less than 65 years of age, and older patients without kidney disease, dementia or cancer would be most likely to benefit from the use of an implantable defibrillator to prevent sudden death.

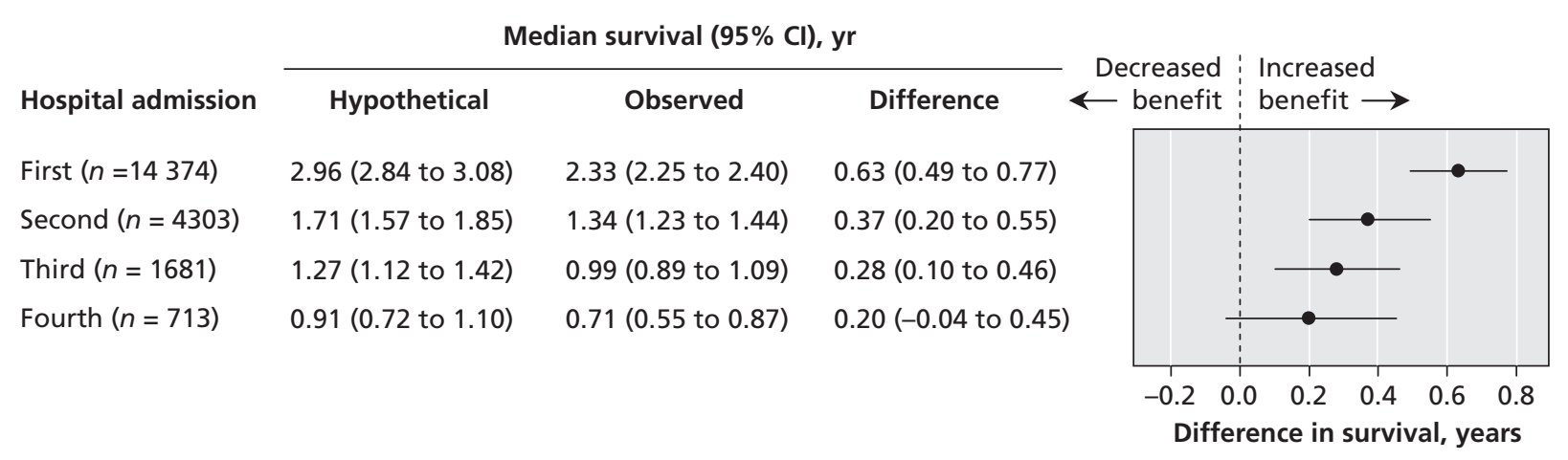

Figure 1: The maximum potential benefit of preventing sudden death with the use of implantable defibrillators among patients admitted to hospital because of heart failure. The values shown represent the difference between the observed survival after each hospital admission and the hypothetical survival whereby all out-of-hospital cardiac deaths were assumed to be preventable. 
In contrast to our observations, information from the US National Cardiovascular Data Registry for 2006-2007 indicates that implantable defibrillators are frequently implanted in older patients with heart failure: $61 \%$ of patients were 65 years or older, and $15 \%$ were 80 years or older. ${ }^{15}$ Prior hospital admission because of heart failure was reported in $58 \%$ of patients, and noncardiac comorbidities were common..$^{15}$

Compared with patients in clinical trials of heart failure, ${ }^{16-18}$ our study population had a substantially lower incidence of cardiac deaths overall and out-of-hospital cardiac deaths in particular. However, patients enrolled in clinical trials tend to be younger and to have fewer comorbidities than the general population of patients with heart failure encountered in the community. Increasing age has previously been associated with a decreased risk of sudden cardiac death, ${ }^{19}$ and having more comorbidities increases the risk of death from noncardiac causes.

In a study population similar to ours, Khand and colleagues ${ }^{20}$ identified 12640 patients in Scotland who had a first admission to hospital because of heart failure and a mean age of 74 years. They found that $50 \%$ of the patients who survived after the first admission died over a 3-year follow-up period and that $43 \%$ of these deaths occurred out of hospital. These findings are similar to our results. The impact of age on the potential cost-effectiveness of preventing sudden death was also modelled by Yao and colleagues..$^{21}$ Although they based their analysis on data from the Cardiac Resynchronization in Heart Failure (CARE-HF) trial, in which patients received resynchronization therapy, similar conclusions can be derived regarding the diminishing impact of the prevention of sudden death among older patients.

\section{Limitations}

Our study has several limitations. First, our definition of outof-hospital cardiac deaths included causes of death in addition to sudden cardiac death. Using this definition we may have overestimated the survival benefit with implantable defibrilla- tors. Second, there are obvious competing risks, especially in older patients, that we did not account for in our analysis. Third, studies have shown that, among patients with symptomatic heart failure, implantable defibrillators prevent only about half of all sudden cardiac deaths..$^{22}$ Fourth, we relied on nosologist-coded causes of death to identify out-of-hospital cardiac deaths. Although such coding has good agreement with physician-adjudicated causes in major categories (e.g., cardiac v. noncardiac), ${ }^{23}$ this method of identifying cardiac deaths could be by exclusion of other obvious causes such as motor vehicle crashes and bleeding and tend to include more than cardiac causes, which may have led to further overestimation of the benefit. Finally, our data did not allow distinction between heart failure due to systolic dysfunction and heart failure with preserved left ventricular function. It has been estimated that the incidence of sudden cardiac death is almost 3 times higher among patients with systolic dysfunction than among patients with heart failure who have a preserved ejection fraction. ${ }^{24}$ Therefore, an optimistic upper boundary of the estimated benefit among patients with systolic dysfunction would be 1.5 times that observed in the overall population of patients with heart failure, half of whom have systolic dysfunction. ${ }^{25-27}$ However, the maximum potential benefit of preventing sudden death would still be less than 6 months after 2 hospital admissions and 5 months after 3 hospital admissions.

Given the multiple limitations in any such analysis of a large population outside of a clinical trial, our study provides a liberal estimate of the limited potential benefit of preventing sudden death among patients with heart failure in the general community.

\section{Conclusion}

Our analysis indicates that the maximum potential benefit of preventing sudden death is limited in patients with repeated hospital admissions related to heart failure. This is particularly true among older patients and among patients with co-

Table 4: Hypothetical* 2-year survival rates in subgroups defined by age, chronic kidney disease, cancer and dementia†

Hospital admission;

hypothetical 2-year survival rate, $\%(95 \% \mathrm{Cl})$

\begin{tabular}{|c|c|c|c|c|}
\hline \multirow[b]{2}{*}{ Subgroup } & & & & \\
\hline & First & Second & Third & Fourth \\
\hline \multicolumn{5}{|l|}{ Age $<65 \mathrm{yr}$} \\
\hline Without chronic kidney disease $(n=1491)$ & $84(82-86)$ & $70(65-76)$ & $62(52-73)$ & $51(33-70)$ \\
\hline With chronic kidney disease $(n=433)$ & $66(61-70)$ & $50(41-58)$ & $48(37-59)$ & $32(16-47)$ \\
\hline \multicolumn{5}{|l|}{ Age $65-80 \mathrm{yr}$} \\
\hline Without chronic kidney disease or dementia $(n=3927)$ & $69(68-71)$ & $58(55-62)$ & $49(43-55)$ & $41(31-51)$ \\
\hline With chronic kidney disease or dementia $(n=1474)$ & $50(48-53)$ & $41(37-45)$ & $34(29-40)$ & $30(22-38)$ \\
\hline \multicolumn{5}{|l|}{ Age $80-90$ yr } \\
\hline Without chronic kidney disease, dementia or cancer $(n=3812)$ & $53(52-55)$ & $43(40-46)$ & $36(31-41)$ & $31(23-40)$ \\
\hline With chronic kidney disease, dementia or cancer $(n=2095)$ & $35(33-37)$ & $29(25-32)$ & $28(23-33)$ & $31(24-38)$ \\
\hline Age $>90$ yr $(n=1142)$ & $34(31-37)$ & $31(26-36)$ & $31(22-41)$ & $24(10-38)$ \\
\hline
\end{tabular}

Note: $\mathrm{Cl}=$ confidence interval.

*Survival rate based on the assumption that all out-of-hospital cardiac deaths could have been prevented.

tSubgroups are defined according to characteristics that are strong predictors of sudden death or overall death among patients with heart failure. 
morbidities. However, patients less than 65 years old as well as older patients without kidney disease, dementia or cancer are most likely to benefit from the prevention of sudden death with the use of implantable defibrillators.

This article has been peer reviewed.

Competing interests: Lynne Warner Stevenson is on an advisory board and receives research support and honoraria from Medtronic Inc. Anju Nohria has received consultant fees from Medtronic Inc. No competing interests declared by Soko Setoguchi, Jeremy Rassen or Sebastian Schneeweiss.

Contributors: All of the authors contributed substantially to the concept and design of the study, and the acquisition, analysis and interpretation of the data. Soko Setoguchi drafted the manuscript. All of the authors revised the manuscript critically for important intellectual content and gave final approval of the version to be published.

Funding: No external funding was received for this research.

\section{REFERENCES}

1. Tsuyuki RT, Shibata MC, Nilsson C, et al. Contemporary burden of illness of congestive heart failure in Canada. Can J Cardiol 2003;19:436-8.

2. American Heart Association. Hospital discharges for cardiovascular diseases - statistics. Dallas (TX): The Association; 2004. Available: www.americanheart.org /downloadable/heart/1136821961654HospDischarges06.pdf (accessed 2006 Jan. 19).

3. Setoguchi S, Stevenson LW, Schneeweiss S. Repeated hospitalizations predict mortality in the community population with heart failure. Am Heart J 2007;154:260-6.

4. Schneeweiss S, Avorn J. A review of uses of health care utilization databases for epidemiologic research on therapeutics. J Clin Epidemiol 2005;58:323-37.

5. Lee DS, Donovan L, Austin PC, et al. Comparison of coding of heart failure and comorbidities in administrative and clinical data for use in outcomes research. Med Care 2005;43:182-8.

6. Birman-Deych E, Waterman AD, Yan Y, et al. Accuracy of ICD-9-CM codes for identifying cardiovascular and stroke risk factors. Med Care 2005;43:480-5.

7. Lee DS, Austin PC, Rouleau JL, et al. Predicting mortality among patients hospitalized for heart failure: derivation and validation of a clinical model. JAMA 2003;290:2581-7.

8. Kiyota Y, Schneeweiss S, Glynn RJ, et al. Accuracy of Medicare claims-based diagnosis of acute myocardial infarction: estimating positive predictive value on the basis of review of hospital records. Am Heart J 2004;148:99-104

9. Winkelmayer WC, Schneeweiss S, Mogun H, et al. Identification of individuals with CKD from Medicare claims data: a validation study. Am J Kidney Dis 2005 46:225-32

10. De Bruin ML, van Hemel NM, Leufkens HG, et al. Hospital discharge diagnoses of ventricular arrhythmias and cardiac arrest were useful for epidemiologic research. J Clin Epidemiol 2005;58:1325-9.
11. Zheng ZJ, Croft JB, Giles WH, et al. Sudden cardiac death in the United States, 1989 to 1998 . Circulation 2001;104:2158-63.

12. Williams JI, Young W. Inventory of studies on the accuracy of Canadian health ad ministrative databases. Toronto (ON): Institute for Clinical Evaluative Sciences; 1996.

13. Moss AJ, Zareba W, Hall WJ, et al. Prophylactic implantation of a defibrillator in patients with myocardial infarction and reduced ejection fraction. N Engl J Med 2002; 346:877-83.

14. Bardy GH, Lee KL, Mark DB, et al. Amiodarone or an implantable cardioverterdefibrillator for congestive heart failure. N Engl J Med 2005;352:225-37.

15. Hammill SC, Stevenson LW, Kadish AH, et al. Review of the registry's first year, data collected, and future plans. Heart Rhythm 2007;4:1260-3.

16. Effect of metoprolol CR/XL in chronic heart failure: Metoprolol CR/XL Randomised Intervention Trial in Congestive Heart Failure (MERIT-HF). Lancet 1999;353:2001-7.

17. Carson P, Anand I, O'Connor C, et al. Mode of death in advanced heart failure: the Comparison of Medical, Pacing, and Defibrillation Therapies in Heart Failure (COMPANION) trial. J Am Coll Cardiol 2005;46:2329-34.

18. Cleland JG, Thygesen K, Uretsky BF, et al. Cardiovascular critical event pathways for the progression of heart failure: a report from the ATLAS study. Eur Heart J 2001; 22:1601-12.

19. Lindenfeld J, Bristow MR. Increasing age decreases the risk of sudden death compared to progressive heart failure in patients with advanced heart failure. Proceedings of the American Heart Association Scientific Session; Chicago; 2006 Nov. 12-15. Dallas (TX): American Heart Association; 2006.

20. Khand AU, Gemmell I, Rankin AC, et al. Clinical events leading to the progression of heart failure: insights from a national database of hospital discharges. Eur Heart J 2001;22:153-64.

21. Yao G, Freemantle N, Calvert MJ, et al. The long-term cost-effectiveness of cardiac resynchronization therapy with or without an implantable cardioverterdefibrillator. Eur Heart J 2007;28:42-51.

22. Greenberg H, Case RB, Moss AJ, et al. Analysis of mortality events in the Multicenter Automatic Defibrillator Implantation Trial (MADIT-II). J Am Coll Cardiol 2004:43:1459-65.

23. Sesso HD, Gaziano JM, Glynn RJ, et al. Value of an Endpoints Committee versus the use of nosologists for validating cause of death. Contemp Clin Trials 2006;27:333-9.

24. Solomon SD, Anavekar N, Skali H, et al. Influence of ejection fraction on cardiovascular outcomes in a broad spectrum of heart failure patients. Circulation 2005; 112:3738-44.

25. Owan TE, Hodge DO, Herges RM, et al. Trends in prevalence and outcome of heart failure with preserved ejection fraction. N Engl J Med 2006;355:251-9.

26. Bhatia RS, Tu JV, Lee DS, et al. Outcome of heart failure with preserved ejection fraction in a population-based study. N Engl J Med 2006;355:260-9.

27. Yancy CW, Lopatin M, Stevenson LW, et al. Clinical presentation, management, and in-hospital outcomes of patients admitted with acute decompensated heart failure with preserved systolic function: a report from the Acute Decompensated Heart Failure National Registry (ADHERE) Database. J Am Coll Cardiol 2006;47:76-84.

Correspondence to: Dr. Soko Setoguchi, Division of

Pharmacoepidemiology and Pharmacoeconomics, 3030-1620 Tremont St., Boston MA 02130, USA; fax 617 232-8602; ssetoguchi@partners.org 